\title{
Hyperhomocysteinemia in Acquired Non-traumatic Paralytic Strabismus: A Case Series
}

\section{ABSTRACT}

Diabetes and hypertension are among the main causes of acquired non-traumatic paralytic strabismus in elderly. They cause ischemic changes in the cranial nerves resulting in paralysis. Recently, hyperhomocyteinemia has emerged as a risk factor in systemic ischemic diseases. Only a few studies have suggested role of homocysteine in acquired abducens palsy.

This article describes six cases ( 2 males, 4 females) with hyperhomocysteinemia, out of 67 patients of acquired non-traumatic strabismus, seen over 10 years from January 2010 to December 2019 . The mean age of patients was 45 years. Three patients had abducens palsy, while two patients had oculomotor palsy and one patient had trochlear nerve palsy. Two elderly females also had co-existing diabetes mellitus and dyslipidemia.

It can be concluded that patients with acquired non-traumatic paralytic strabismus should be evaluated for serum homocysteine.

Keywords: Abducens, Oculomotor, Serum homocysteine, Trochlear nerve palsy

\section{CASE SERIES}

The most common causes of non-traumatic paralytic strabismus in elderly are diabetes and hypertension as they cause ischemic changes in the cranial nerves [1-3]. In recent times, hyperhomocysteinemia has been reported as a risk factor for acquired abducens palsy [4]. In the present article, we report six patients of acquired paralytic strabismus that had raised serum homocysteine levels.

The hospital records of patients with non-traumatic acquired incomitant strabismus with raised serum homocysteine levels, from January 2010 to January 2019 were evaluated. All of these patients were evaluated for the risk factors like hypertension, diabetes mellitus, dyslipidemia, viral fever and collagen vascular disorders. Magnetic Resonance Imaging (MRI) of brain (with contrast) was done wherever indicated.

A total of 67 such patients with non-traumatic acquired paralytic strabismus were identified, from January 2010 to December 2019. Of these, six patients were identified that had raised serum homocysteine levels. The mean age of patients with hyperhomocysteinemia was 45 years, youngest patient being nineyear-old boy and the oldest patient was 75-year-old female. The demographic profile of patients is described in [Table/Fig-1].

All the patients had normal values of Erythrocyte Sedimentation Rate (ESR) and C-Reactive Protein (CRP). The mean serum homocysteine levels were 20.79 $\mu \mathrm{mol} / \mathrm{L}$ (range: 17.63-24.25 $\mathrm{mol} / \mathrm{L}, \mathrm{SD}: 2.48 \mu \mathrm{mol} / \mathrm{L}$, normal range 3.9-13.9 $\mu \mathrm{mol} / \mathrm{L}$, chemiluminescence method).

There were three patients (Patient No. 1, 2 and 3) with abducent nerve palsy. All these patients had limited abduction in the affected eye. Two patients (Patient no. 4 and 5) had oculomotor nerve paresis. Both of these presented with limited adduction, depression and elevation of the affected eye as well as ptosis. Pupil was spared in both of these cases. Patient No. 5 was a known diabetic and hypertensive also. Her glycosylated haemoglobin ( $\mathrm{HbA1C}$ ) was $8.5 \%$ and lipids were also deranged. Patient No. 6 had right eye superior oblique palsy. She presented with vertical diplopia. There was limited levodepression of right eye. She had right hypertropia of 6 Prism Dioptres (PD) in primary gaze increasing to 14 PD in left gaze. The hypertropia also increased on right head tilt.

Neuroimaging was ordered in all young patients and in those where risk factors like diabetes, hypertension or dyslipidemia were not found. It was not done in patient no. 2 and 5 . In the rest, MRI brain with contrast did not reveal any abnormality [Table/Fig-2-7].

\section{DISCUSSION}

Non-traumatic paralytic strabismus is more common in older age group, and the most common cause being vasculopathy. In a population based study on the 753 new onset strabismus adult cases, paralytic strabismus $(44.2 \%)$ was found to be the most common type, followed by convergence insufficiency (15.7\%), small angle hypertropia (13.3\%) and divergence insufficiency (10.6\%) [5].

Homocysteine, a derived sulfur-containing and non-proteinogenic amino acid is formed in trace amount during the metabolism of essential amino acid, methionine. The metabolism of homocysteine occurs through the remethylation to methionine or conversion to cysteine which requires enzymes and coenzymes such as vitamin B6, B12, and methyl folic acid. Deficiencies in these vitamins

\begin{tabular}{|l|c|c|c|c|c|c|c|c|}
\hline Patient No. & Age (Years) & Gender & Cranial nerve involved & Eye & Serum homocysteine $\mu \mathrm{mol} / \mathbf{L}$ & Glycosylated haemoglobin (\%) & Lipid profile & MRI brain \\
\hline 1 & 58 & Female & 6 & Left & 18.48 & 6.2 & Normal & Normal \\
\hline 2 & 61 & Female & 6 & Right & 22.76 & 7.1 & Deranged & Not done \\
\hline 3 & 35 & Male & 6 & Right & 22.55 & 5.7 & Normal & Normal \\
\hline 4 & 9 & Male & 3 & Left & 17.63 & Not done & Not done & Normal \\
\hline 5 & 75 & Female & 3 & Right & 19.12 & 8.5 & Deranged & Not done \\
\hline 6 & 32 & Female & 4 & Right & 24.25 & 5.6 & Normal & Normal \\
\hline
\end{tabular}



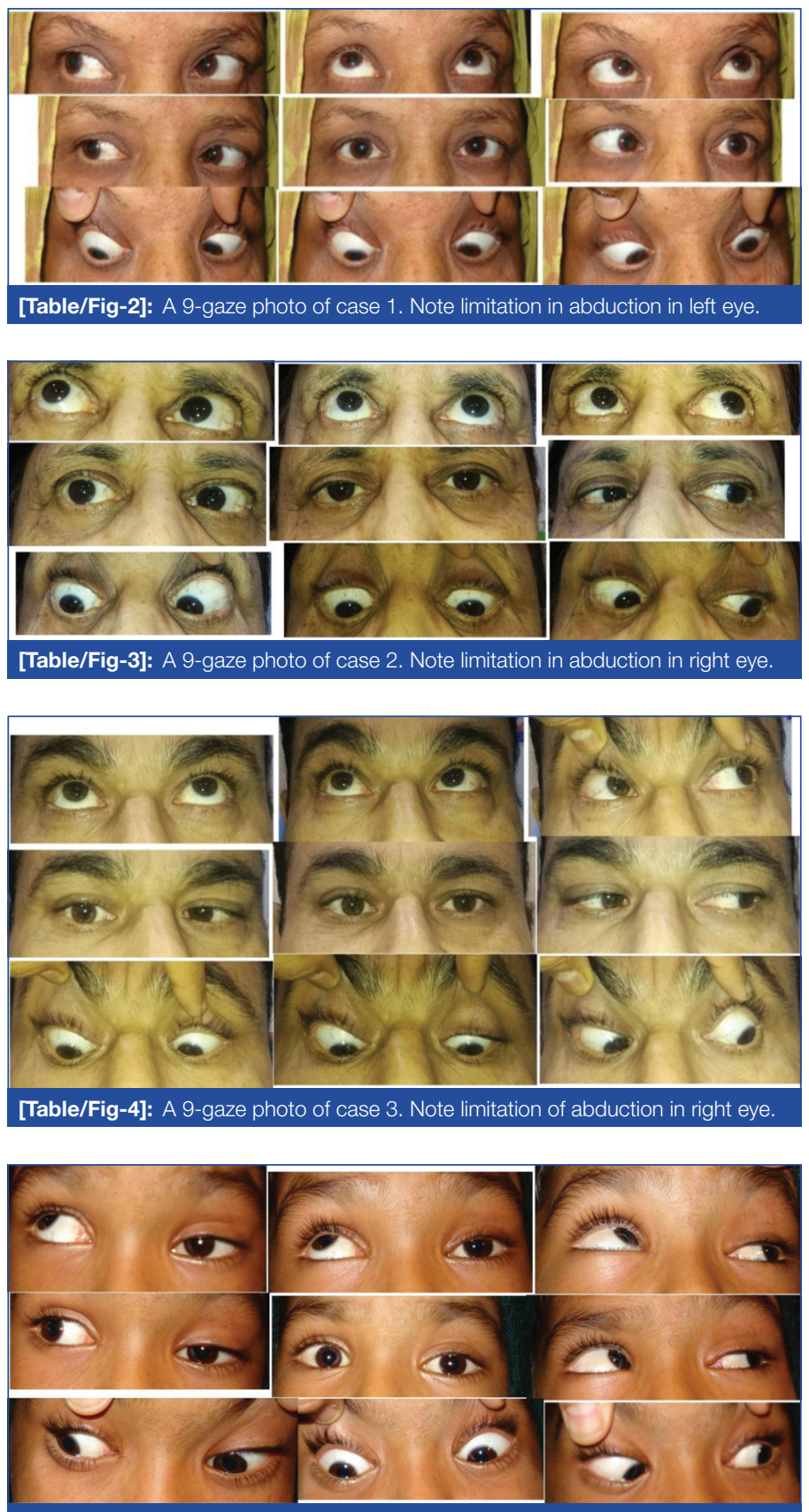

[Table/Fig-5]: A 9-gaze photo of case 4. Note ptosis, limitation in elevation, depression and adduction in left eye.
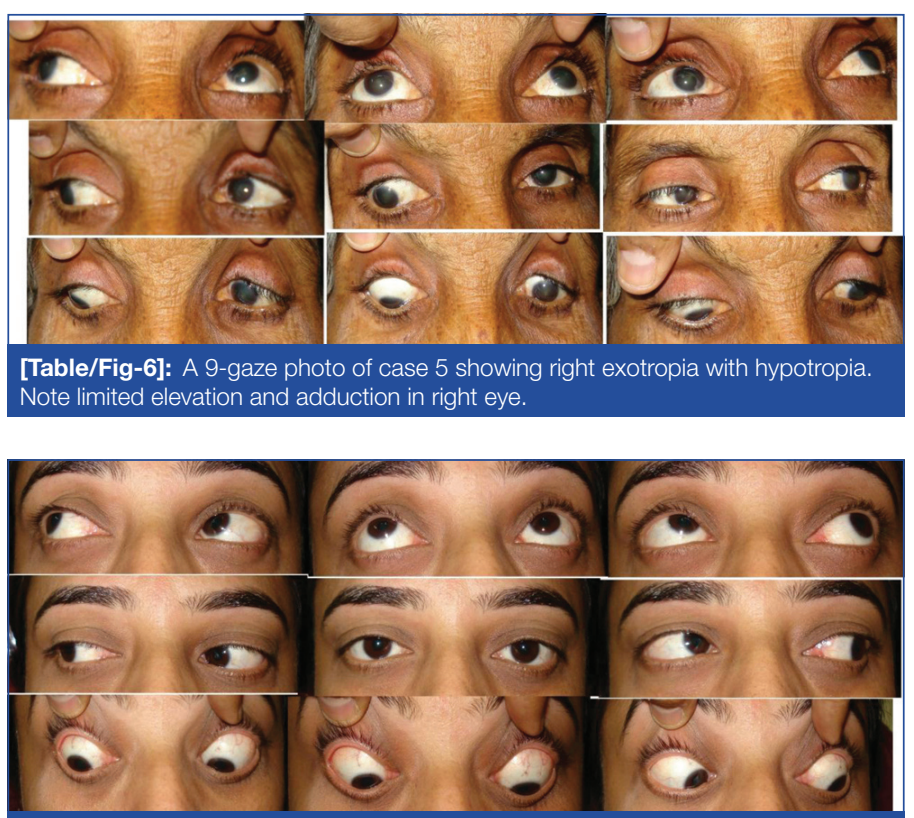

[Table/Fig-7]: A 9-gaze photo of case 6 with right superior oblique palsy. Note limited levodepression in the right eye. are associated with hyperhomocysteinemia- an abnormally very high level of homocysteine in blood. Hyperhomocysteinemia has been implicated in the pathogenesis of a variety of diseases including cardiovascular and neurodegenerative disorders. Hyperhomocysteinemia is associated with increase in risk of several diseases like neural tube defects, congenital heart defects, atherosclerosis, cardiovascular disorders, diabetes, Down syndrome, Alzhiemer's disease and breast cancer [6].

In the eye, hyperhomocysteinemia is suggested as a possible risk factor for many diseases including retinal arterial atherosclerosis, macular degeneration and optic atrophy due to retinal microvascular occlusions, Non-arteritic Ischemic Optic Neuropathy (NAION), cataract, glaucoma and exudative age related macular degeneration [7].

A meta-analysis of studies on retinal vaso-occlusive diseases showed significantly higher levels of plasma homocysteine levels in patients with central retinal vein occlusion, branch retinal vein occlusion and retinal artery occlusion as compared to controls [8]. Many studies also showed association of hyperhomocysteinemia and diabetic retinopathy [9-12]. Increased plasma homocysteine has been reported in cases of pseudo-exfoliation glaucoma $[13,14]$ and age related macular degeneration $[15,16]$.

Sachdeva $\mathrm{V}$ et al., described acquired abducens palsy in four patients in whom no other cause could be found [4]. They evaluated only the patients with abducens palsy, found a female preponderance (3 out of 4 patients) and their patients were younger with mean age of 25 years. In the preset series, the mean age of patients was 45 years and four out of six patients were females. Hyperhomocysteinemia is present in not only abducens palsy patients, but also in patients with oculomotor palsy and trochlear nerve palsy. The patient no. 2 was diabetic, while patient number 5 was both diabetic and hypertensive. Both these patients were also dyslipidemic. Moreover, hyperhomocysteinemia was found in 2 patients above 60 years of age. MRI brain was not done in these two patients.

Park SJ et al., found that patients having oculomotor paresis have high risk of developing stroke (hazard ratio 4.65) [17]. They suggested that such patients should be monitored closely and their risk factors should be taken care of. Kim $\mathrm{K}$ et al., have studied 153 cases of paralytic strabismus and found vascular cause to be the most common aetiology for it (54.9\% of cases) [18]. Vascular group included those patients with diabetes mellitus, hypertension, hypercholesterolemia and those with microangiopathy or infarction evident on MRI brain. The other causes included idiopathic (28.1\%), trauma (8.5\%), neoplasm (5.88\%) and aneurysm (2.61\%). However, they did not evaluate the serum homocysteine level. It is possible that many of the idiopathic and vascular cases could be having raised serum homocysteine levels.

Sowbhagya $\mathrm{HN}$ et al., have found ocular involvement in 25 (42.3\%), out of 59 patients with hyperhomocysteinemia [19]. The ocular findings included papilledema, branch retinal vein occlusion, nonarteritic anterior ischemic optic neuropathy, temporal optic disc pallor and field defects with normal fundus. A total of $54.3 \%$ of the patients had co-morbid conditions like diabetes and hypertension. In the present series, two patients had diabetes and one of these also had hypertension. None of the patients suffered from cranial nerve palsy.

One of the limitation of the present series is that serum vitamin B12 and serum folate levels were not evaluated. Vitamin B12 and folic acid, essential cofactors in homocysteine metabolism, are known determinants of serum homocysteine concentrations. Deficiency of either Vitamin B12 or folic acid can cause elevated levels of homocysteine [20]. 


\section{CONCLUSION(S)}

Patients with acquired non-traumatic cranial nerve palsies may be evaluated for raised serum homocysteine. Hyperhomocysteinemia could be a contributing factor causing ischemia of the cranial nerves resulting in paralytic squint, and it can co-exist with other risk factors like diabetes and dyslipidemia.

\section{REFERENCES}

[1] Patel SV, Holmes JM, Hodge DO, Burke JP. Diabetes and hypertension in isolated sixth nerve palsy: A population-based study. Ophthalmology. 2005;112(5):760-63.

[2] Sanders SK, Kawasaki A, Purvin VA. Long-term prognosis in patients with vasculopathic sixth nerve palsy. Am J Ophthalmol. 2002;134(1):81-84.

[3] Choung HK, Chang BL. Clinical features of ischemic ophthalmoplegia caused by diabetes mellitus or hypertension. J Korean Ophthalmol Soc. 2002;43(1):131-35.

[4] Sachdeva V, Mittal V, Pathengay A, Kekkunaya R, Gupta A, Rao BV. Isolated abducens palsy with hyperhomocysteinemia: Association and outcomes. Indian J Ophthalmol. 2013;61(10):598-600. doi: 10.4103/0301-4738.121089.

[5] Martinez-Thompson JM, Diehl NN, Holmes JM, Mohney BG. Incidence, types and lifetime risk of adult-onset strabismus. Ophthamology. 2014;121(4):877-82. doi:10.1016/j.ophtha.2013.10.030.

[6] Brustolin S, Giugliani R, Félix TM. Genetics of homocysteine metabolism and associated disorders. Braz J Med Biol Res. 2010;43(1):01-07.

[7] Manresa N, Mulero J, Zafrilla P. Homocysteine: Biosynthesis and health implications hyperhomocysteinemia and association of eye disease. $1^{\text {st }} \mathrm{ed}$. New York: Nova Science Publishers; 2003.

[8] Cahill MT, Stinett SS, Fekrat S. A meta-analysis of plasma homocysteine, serum folate, serum B12 and thermolabile MTHFR genotype as risk factors for retinal vascular occlusive disease. Am J Ophthalmol. 2003;136(6):1136-50.

[9] Looker HC, Fagot CA, Gunter EW, Pfeiffer CM, Narayan KMV, Knowler WC, et al. Homocysteine as a risk factor for nephropathy and retinopathy in Type 2 diabetes. Diabetologia. 2003;46(6):766-72.
[10] Vaccaro O, Ingrosso D, Rivellese A, Greco G, Riccardi G. Moderate hyperhomocysteinemia and retinopathy in insulin-dependent diabetes. Lancet. 1997;349(9058):1102-03.

[11] Goldstein M, Leibovitch I, Yeffimov I, Gavendo S, Sela BA, Loewenstein A Hyperhomocysteinemia in patients with diabetes mellitus with and without retinopathy. Eye. 2004;18(5):460-65.

[12] Huang EJ, Khu WW, Chen YJ, Chen TH, Chang M, Lu MC, et al. Homocysteine and other biochemical parameters in Type 2 diabetes mellitus with different diabetic duration or diabetic retinopathy. Clin Chim Acta. 2006;366(1-2):293-98.

[13] Vessani RM, Ritch R, Liebmann JM, Jofe M. Plasma homocysteine is elevated in patients with exfoliation syndrome. Am J Ophthalmol. 2003;136(1):41-46.

[14] Leibovitch I, Kurtz S, Shemesh S, Goldstein M, Sela BA, Lazar M, et al. Hyperhomocysteinemia in psuedoexfoliation glaucoma. J Glaucoma. 2003;12(1):36-39.

[15] Axer-Siegel R, Bourla D, Ehrlich R, Dotan G, Benjamini Y, Gavendo S, et al. Association of neovascular age-related macular degeneration and hyperhomocysteinemia. Am J Ophthalmol. 2004;137(1):84-89.

[16] Coral K, Raman R, Rathi S, Rajesh M, Sulochana KN, Angayarkanni N, et al. Plasma homocysteine and total thiol content in patients with exudative age-related macular degeneration age-related macular degeneration. Eye. 2006;20(2):203-07.

[17] Park SJ, Yang HK, Byun SJ, Park KH, Hwang JM. Oculomotor nerve palsy and increased risk of strokes in general population. PLoS One. 2018;13(10):e0205428. doi: 10.1371/journal.pone.0205428. eCollection 2018.

[18] Kim K, Noh SR, Kang MS, Jin KH. Clinical course and prognostic factors of acquired third fourth and sixth cranial nerve palsies in Korean patients. Korean J Ophthalmol. 2018:32(3):221-27. doi:10.3341/kjo.2017.0051. Epub 2018 Mar 20

[19] Sowbhagya HN, Kothari M, Kumar LK, Nikhil N. Ocular Manifestations of hyperhomocysteinemia and their response to therapeutic modalities. Int J Sci Stud. 2015;3(3):55-59

[20] Klee GG. Cobalamin and folate evaluation: Measurement of methylmalonic acid and homocysteine vs vitamin B (12) and folate. Clin Chem. 2000;46:1277-83.

\section{PARTICULARS OF CONTRIBUTORS:}

1. Consultant, Department of Laboratory Medicine, LJ Eye Institute, Ambala City, Haryana, India.

2. Consultant, Department of Paediatric Ophthalmology and Strabismus, LJ Eye Institute, Ambala City, Haryana, India.

NAME, ADDRESS, E-MAIL ID OF THE CORRESPONDING AUTHOR:

Dr. Priyanka Sharma,

House No. 265, FF, Sector 35A, Chandigarh, India.

E-mail: mintusharma@yahoo.com
PLAGIARISM CHECKING METHODS: [Jain Het al.]

- Plagiarism X-checker: Mar 03, 2020

- Manual Googling: Mar 24, 2020

- iThenticate Software: Mar 28, 2020 (8\%)
ETYMOLOGY: Author Origin

\section{AUTHOR DECLARATION:}

- Financial or Other Competing Interests: None

- Was informed consent obtained from the subjects involved in the study? Yes

- For any images presented appropriate consent has been obtained from the subjects. Yes
Date of Submission: Feb 18, 2020

Date of Peer Review: Mar 13, 2020

Date of Acceptance: Mar 24, 2020 Date of Publishing: Apr 01, 2020 